Illinois State University

ISU ReD: Research and eData

Theses and Dissertations

3-27-2019

\title{
Single Leg Hop Landing Analysis in Patients with Chronic Ankle Instability, Lateral Ankle Sprain Copers, and Healthy Individuals
}

Jordyn Ashlyn Rine

Illinois State University, jordynrine@gmail.com

Follow this and additional works at: https://ir.library.illinoisstate.edu/etd

Part of the Kinesiology Commons

\section{Recommended Citation}

Rine, Jordyn Ashlyn, "Single Leg Hop Landing Analysis in Patients with Chronic Ankle Instability, Lateral Ankle Sprain Copers, and Healthy Individuals" (2019). Theses and Dissertations. 1080.

https://ir.library.illinoisstate.edu/etd/1080

This Thesis is brought to you for free and open access by ISU ReD: Research and eData. It has been accepted for inclusion in Theses and Dissertations by an authorized administrator of ISU ReD: Research and eData. For more information, please contact ISUReD@ilstu.edu. 


\section{SINGLE LEG HOP LANDING ANALYSIS IN PATIENTS WITH CHRONIC ANKLE INSTABILITY, LATERAL ANKLE SPRAIN COPERS, AND HEALTHY INDIVIDUALS}

\section{JORDYN ASHLYN RINE}

\section{Pages}

CONTEXT: There are an estimated 28,000 ankle injuries that occur per day in the United States, thus making the pathology one of the most common sports-related injuries. Lateral ankle sprains account for $80 \%$ of all athletic injuries and approximately $73 \%$ will suffer from a recurrent injury. The residual symptoms that linger following repetitive lateral ankle sprains are often correlated with chronic ankle instability (CAI). Lateral ankle sprain (LAS) copers successfully cope with the damage that results from sustaining a lateral ankle sprain, whereas CAI patients suffer from residual symptoms. Traditional measures of COP from force-plate data are useful in evaluating the function and stability of the foot. Compared to healthy individuals, patients diagnosed with CAI demonstrate poor postural control that results in altered COP locations during a single-limb static balance task on a force-plate. Most of the literature within CAI research has attributed movement dysfunction to impaired sensorimotor function. This somatic dysfunction reduces the ability of the neuromuscular system to provide proprioceptive feedback as well as producing efficient movement outcomes. PURPOSE: The purpose of this study was to determine the differences that exist in dynamic postural control strategies between CAI vs LAS copers vs healthy individuals in a single leg hopping task. METHODS: This was a case-control analytical study conducted in the biomechanics lab at Illinois State University that 
used previously collected data by Jagodinsky et. al. Forty-five recreationally active individuals (14 healthy, 15 copers, and 16 with CAI) between the ages of 19 and 30 were instructed to hop on a force plate for 3 blocks of nine hops each. Center of pressure (COP) data was analyzed in both the $\mathrm{x}$ and $\mathrm{y}$ directions by conducting a MANOVA to detect between group differences. RESULTS: Three MANOVAs were performed evaluating seven different variables that were grouped by measures of excursion, variability, and velocity. There was no significant difference between groups for the excursion $(\mathrm{p}=0.82)$, variability $(\mathrm{p}=0.63)$, and velocity $(\mathrm{p}=0.79)$ measures on the combined dependent variables. CONCLUSION: Our findings suggest that there were no biomechanical differences present amongst individuals with ankle dysfunction during a SL hop task. Future research should examine a more difficult dynamic stabilization task since we believe that the SL hop was not difficult enough to truly examine the between groups differences that might exist.

KEYWORDS: Chronic Ankle Instability (CAI), Lateral Ankle Sprain (LAS) Coper, Center of Pressure (COP), SL Hop Landing Analysis 


\section{SINGLE LEG HOP LANDING ANALYSIS IN PATIENTS WITH CHRONIC ANKLE INSTABILITY, LATERAL ANKLE SPRAIN COPERS, AND HEALTHY INDIVIDUALS}

JORDYN ASHLYN RINE

A Thesis Submitted in Partial Fulfillment of the Requirements for the Degree of

MASTER OF SCIENCE

School of Kinesiology and Recreation

ILLINOIS STATE UNIVERSITY 
(C) 2019 Jordyn Ashlyn Rine 
SINGLE LEG HOP LANDING ANALYSIS IN PATIENTS WITH CHRONIC ANKLE INSTABILITY, LATERAL ANKLE SPRAIN COPERS, AND HEALTHY INDIVIDUALS

JORDYN ASHLYN RINE

COMMITTEE MEMBERS:

Justin Stanek, Co-Chair

Adam Jagodinsky, Co-Chair 


\section{ACKNOWLEDGMENTS}

I would firstly like to express my gratitude to my committee members, Dr. Justin Stanek and Dr. Adam Jagodinsky, for their continual guidance and reassurance throughout the process of writing this thesis. I would also like to thank my parents, Mary Jo and Kevin Rine, my extended family, my girlfriend, Stephanie Stephens, and a number of close friends and classmates for their endless encouragement and support.

J. A. R 


\section{CONTENTS}

Page

ACKNOWLEDGMENTS

$\begin{array}{ll}\text { CONTENTS } & \text { ii }\end{array}$

TABLES

CHAPTER I: SINGLE LEG HOP LANDING ANALYSIS IN PATIENTS WITH CHRONIC ANKLE INSTABILITY, LATERAL ANKLE SPRAIN COPERS, AND HEALTHY

INDIVIDUALS 1

Introduction $\quad 1$

Methods 3

Research Design 3

Instrumentation $\quad 3$

Participants 3

$\begin{array}{ll}\text { Procedures } & 6\end{array}$

$\begin{array}{ll}\text { Data Processing } & 6\end{array}$

$\begin{array}{ll}\text { Statistical Analysis } & 7\end{array}$

$\begin{array}{ll}\text { Results } & 7\end{array}$

$\begin{array}{ll}\text { Discussion } & 9\end{array}$

CHAPTER II: EXTENDED REVIEW OF THE LITERATURE 14

$\begin{array}{ll}\text { Anatomy } & 14\end{array}$

$\begin{array}{ll}\text { Bone/Joint } & 14\end{array}$ 
Muscle

Ligament

Pathomechanics of a Lateral Ankle Sprain

Lateral Ligament Orientation and Order of Failure

Dynamic Stabilization

Ankle Mortise Bony Congruency

Pathomechanics of Chronic Ankle Instability

Mechanical Instability

Functional Instability

Lateral Ankle Sprain Copers

Definition

Minimal Inclusion Criteria

Differences between CAI and LAS Copers

Self-Reported Disability

Mechanical Changes

Sensorimotor Alterations

Recent Research 


\section{TABLES}

Table

Page

1. Descriptive Statistics: Participants 4

2. Group Allocation 4

3. Descriptive Statistics: Subjective Assessment Survey Outcome Score 5

4. Descriptive Statistics: Self-Reported Percent Level of Function 5

5. Descriptive Statistics: AII "Yes" Responses 6

6. Descriptive Statistics: Excursion $\quad 8$

7. Descriptive Statistics: Variability $\quad 8$

8. Descriptive Statistics: Velocity 9

9. MANOVA Results 9 


\section{CHAPTER I: SINGLE LEG HOP LANDING ANALYSIS IN PATIENTS WITH CHRONIC}

ANKLE INSTABILITY, LATERAL ANKLE SPRAIN COPERS, AND HEALTHY

\section{INDIVIDUALS}

\section{Introduction}

It has been reported that 28,000 ankle injuries occur per day in the United States, thus making the pathology one of the most common sports-related injuries. ${ }^{1,2}$ Lateral ankle sprains account for $80 \%$ of all athletic injuries, with an estimated two million ankle sprains occurring in the United States each year. ${ }^{3}$ In addition to the high number of individuals who sprain their ankle, approximately $73 \%$ will suffer from a recurrent injury. ${ }^{3}$ Approximately $59 \%$ of those individuals will have residual complaints such as pain, instability, or weakness in the injured ankle that may last up to three years. ${ }^{3}$

Even though the mechanism of injury for both acute and recurrent lateral ankle sprains is the same, the changes that occur after the initial injury are what predispose individuals to recurrent sprains. ${ }^{4}$ The residual symptoms that linger following repetitive lateral ankle sprains are often correlated with chronic ankle instability (CAI). ${ }^{5}$ This condition is categorized by repetitive ankle sprains, decreased self-reported function due to the ankle injuries, and incidences of the ankle "giving way". ${ }^{6}$ Within CAI research, it is recommended to use lateral ankle sprain (LAS) copers as a comparison group to CAI patients by the International Ankle Consortium. ${ }^{7}$ By utilizing a comparison group, such as LAS copers, researchers may provide stronger and more reliable results than when compared to uninjured or healthy control subjects, due to the exposure to the injury and not developing CAI ${ }^{8}$ These individuals successfully cope with the damage that results from sustaining a lateral ankle sprain, whereas CAI patients suffer from residual symptoms. ${ }^{8}$ LAS copers, as defined by Wikstrom et al., are "individuals that have a history of at 
least one LAS that occurred at least 12 months ago and do not complain of disability and/or giving way episodes since their injury."8 Interestingly, these patients who do not exhibit longterm mal-adaptations to ankle injuries are able to manage their impairments and produce functional outcomes from undetermined mechanisms (e.g. patterns of structural impairment, neuromotor adaptations, or psychological responses). ${ }^{9}$

Recent research has shown that there are many potential contributing mechanical, neuromuscular, functional, and/or perceived deficits that may persist long after the tissues have healed and interventions performed have been completed following an acute ankle sprain. ${ }^{10-21}$ Compared to healthy individuals, patients diagnosed with CAI demonstrate poor postural control that results in altered COP locations during a single-limb static balance task on a force-plate. ${ }^{22}$ Most of the literature within CAI research has attributed movement dysfunction to impaired sensorimotor function..$^{23,24}$ This somatic dysfunction reduces the ability of the neuromuscular system to provide proprioceptive feedback as well as producing efficient movement outcomes. ${ }^{23,24}$ Traditional measures of COP from force-plate data are useful in evaluating the function and stability of the foot. ${ }^{25}$ Several studies have observed COP force-plate data in static tasks to detect balance deficits in individuals with CAI. ${ }^{26,27}$ Some authors suggest using functional tests to magnify the degree of sensorimotor deficits present in patients with CAI. ${ }^{28,29}$

Given the prevalence of lateral ankle sprains and the poor outcomes that exist following the initial sprain, it becomes important to identify the differences that exist amongst populations affected by lateral ankle sprains in order to decrease the pathologic cascade that results in recurrent lateral ankle sprains. Within CAI research, there has been ample research conducted with the use of stationary tasks examining various variables. However, there has been little to no research performed examining these groups within a dynamic SL hop task. Therefore, the 
purpose of this study was to determine the biomechanical differences, in COP data, that exist amongst lateral ankle sprain copers and individuals with CAI. It was hypothesized that there would be a clinically relevant biomechanical difference between LAS copers and CAI individuals and that there would be a minimal difference between LAS copers and healthy individuals.

\section{Methods}

\section{Research Design}

This was a case-control analytical study conducted in the biomechanics lab at Illinois State University that used previously collected data by Jagodinsky et. al. ${ }^{30}$ The independent variable for this study was group, and the dependent variables consisted of seven measurements for center of pressure (COP) data in both $\mathrm{x}$ and $\mathrm{y}$ directions.

\section{Instrumentation}

The equipment used in this study was from the Sport Biomechanics Laboratory at Auburn University. Measurement of segment motion during hopping trials was obtained using a 10-camera Vicon MX optical motion capture system $\left(V_{i c o n}{ }^{\circledR}\right.$, Los Angeles, CA, USA) with a sampling frequency of $200 \mathrm{~Hz} .{ }^{31}$ The task was performed on an embedded force plate and there was a dedicated $30 \mathrm{~cm} \times 30 \mathrm{~cm}$ perimeter to perform the hopping task.

\section{Participants}

Upon approval by the institutional review board at Auburn University, 48 recreationally active individuals between the ages of 19-30 consented to participate in the study (Table 1). By using this age range, the author was reflecting a convenience sampling of university students. Initially, participants were excluded if they reported a lower extremity injury within the past 3 months, neurological impairments, movement disorders other than ankle dysfunction, or a 
previous lower extremity fracture or surgery. Once the subjects passed the initial screening, they were delegated to the appropriate group for further screening to make sure that they qualified for each groups' specific inclusion criteria. Each group consisted of 16 participants ( 10 female, 6 male) who were matched for gender and limb dominance. However, for the purposes of this analytical study, three participants (2- Healthy, 1- LAS Coper) were excluded due to equipment malfunction (Table 2).

Table 1. Descriptive Statistics: Participants

\begin{tabular}{|c|c|c|c|}
\hline Variable & Group & Mean & SD \\
\hline \multirow{3}{*}{ Age (yrs) } & Healthy & 23.1 & 1.9 \\
\cline { 2 - 4 } & LAS Copers & 22.4 & 2.9 \\
\cline { 2 - 4 } & CAI & 23.3 & 3.1 \\
\hline \multirow{3}{*}{ Height (m) } & Healthy & 1.68 & 0.08 \\
\cline { 2 - 4 } & LAS Copers & 1.69 & 0.08 \\
\cline { 2 - 4 } & CAI & 1.72 & 0.09 \\
\hline \multirow{3}{*}{ Mass $(\mathrm{kg})$} & Healthy & 70.94 & 12.60 \\
\cline { 2 - 4 } & LAS Copers & 75.45 & 19.26 \\
\cline { 2 - 4 } & CAI & 77.84 & 17.19 \\
\hline
\end{tabular}

Table 2. Group Allocation

\begin{tabular}{|c|c|}
\hline Group & $\mathbf{N}$ \\
\hline Healthy & 14 (10 female, 4 male $)$ \\
\hline LAS Copers & $15(10$ female, 5 male $)$ \\
\hline CAI & $16(10$ female, 6 male $)$ \\
\hline
\end{tabular}

Inclusion criteria used for the LAS coper group was the recommended criteria established by Wikstrom and Brown $\left.{ }^{8}: 1\right)$ At least one lateral ankle sprain that necessitated immobilization or assisted weight bearing for at least three days. 2) For at least 12 months before testing individuals had no pain, weakness, or instability in the involved ankle and had resumed all preinjury activities without limitation. 3) Minimal self-reported disability.

Inclusion criteria used for the CAI group was the recommended criteria established by Gribble et. al ${ }^{32}:$ 1) History of at least one lateral ankle sprain, occurring greater than 12 months 
prior to the study, requiring a period of assisted weight bearing or immobilization. 2) Chronic weakness, pain, instability or recurrent episodes of giving way in the involved ankle (without injury), attributed to the original injury. 3) Two or more episodes of the involved ankle giving way between three to 12 months of the study. 4) No observed ankle injury or participation in rehabilitation associated with the involved limb within the past three months of the study. In addition to the criteria outlined above, The Foot and Ankle Ability Measure (FAAM), Foot and Ankle Ability Measure Sport (FAAM-S), and Ankle Instability Instrument (AII) were employed to quantify dysfunction related to leg, foot and ankle musculoskeletal conditions, and functional ankle instability. Individuals in the CAI group met the following scoring criteria: 1) Five recorded "yes" answers on the AII (Table 5). 2) A score of $\leq 90 \%$ on the FAAM (Tables $3,4)$. 3) A score of $\leq 80 \%$ on FAAM-S (Tables 3,4).

Table 3. Descriptive Statistics: Subjective Assessment Survey Outcome Percentage Score

\begin{tabular}{|c|c|c|c|}
\hline Variable & Group & Mean & SD \\
\hline \multirow{3}{*}{ FAAM } & Healthy & $99.7 \%$ & $1.3 \%$ \\
\cline { 2 - 4 } & LAS Copers & $99.5 \%$ & $0.9 \%$ \\
\cline { 2 - 4 } & CAI & $85.2 \%$ & $5.5 \%$ \\
\hline \multirow{3}{*}{ FAAM-S } & Healthy & $98.0 \%$ & $3.8 \%$ \\
\cline { 2 - 4 } & LAS Copers & $97.5 \%$ & $3.6 \%$ \\
\cline { 2 - 4 } & CAI & $68.0 \%$ & $9.7 \%$ \\
\hline
\end{tabular}

Table 4. Descriptive Statistics: Self-Reported Percent Level of Function

\begin{tabular}{|c|c|c|c|}
\hline Variable & Group & Mean & SD \\
\hline \multirow{3}{*}{ FAAM } & Healthy & $98.6 \%$ & $3.1 \%$ \\
\cline { 2 - 4 } & LAS Copers & $99.0 \%$ & $2.1 \%$ \\
\cline { 2 - 4 } & CAI & $88.9 \%$ & $6.6 \%$ \\
\hline \multirow{3}{*}{ FAAM-S } & Healthy & $96.1 \%$ & $6.3 \%$ \\
\cline { 2 - 4 } & LAS Copers & $99.0 \%$ & $2.1 \%$ \\
\cline { 2 - 4 } & CAI & $78.8 \%$ & $11.1 \%$ \\
\hline
\end{tabular}


Table 5. Descriptive Statistics: AII "Yes" Responses

\begin{tabular}{|c|c|c|c|}
\hline Variable & Group & Mean & SD \\
\hline \multirow{3}{*}{ AII } & Healthy & 1 & 1 \\
\cline { 2 - 4 } & LAS Copers & 3 & 1 \\
\cline { 2 - 4 } & CAI & 7 & 1 \\
\hline
\end{tabular}

\section{Procedures}

Prior to participant instruction, the hopping task was demonstrated by a researcher and they gave the participant the analogy of jumping rope. Each participant was instructed to hop on the involved limb at a self-selected frequency with their hands resting on their hips or shoulders. The task was performed on an embedded force plate and there was a dedicated $30 \mathrm{~cm} \times 30 \mathrm{~cm}$ perimeter to perform the hopping task. While the subjects were performing the task, a researcher observed the foot placement during each block of trials. If the subject's foot went outside of the designated perimeter, the trial was discarded, and they were asked to repeat the block of trials. Participants completed three blocks of hopping, each consisting of nine trials and a minimum of 30 seconds was given in between trials. In order to combat the effects of movement initiation and cessation, the first and last two trials within each block were discarded leaving each block of trials with 5 viable hops. Thus, a total of 15 single-leg hops were analyzed per participant.

\section{Data Processing}

Center of Pressure (COP) data were filtered using a lowpass filter set at $6 \mathrm{~Hz}$. All dependent variables were calculated using a custom MATLAB code (MATLAB ${ }^{\circledR}$ R2013b, Mathworks, Inc., Natick, MA). The dependent variables extracted from the COP data were excursion, displacement, root mean square (RMS), standard deviation (SD), mean velocity, peak velocity, and negative peak velocity in both the $\mathrm{x}$ and $\mathrm{y}$ directions. Excursion in the $\mathrm{x}$ direction was defined as the total medial to lateral path taken from foot contact during stance phase, while excursion in the $\mathrm{y}$ direction was the total anterior to posterior path. Displacement in both the $\mathrm{x}$ 
and y directions were calculated from subtracting the initial foot position from the final foot position. Measures of variability were analyzed through the root mean square and standard deviation as normally calculated. Velocity was measured through the mean, peak velocity in the medial direction (positive), and peak velocity in the lateral direction (negative). Foot dominance was accounted for by reverse coding for the correct foot being analyzed.

\section{Statistical Analysis}

The excursion, displacement, mean velocity, peak velocity, and negative peak velocity raw data violated test normality assumptions and was transformed to square roots and absolute values in order to run the statistical tests in an appropriate manner. A multivariate analysis of variance (MANOVA) with one fixed factor at three levels (group: CAI, LAS copers, healthy) was performed to evaluate the biomechanical differences between groups on all outcome variables. Three MANOVAs were performed evaluating seven different variables that were grouped by measures of excursion, variability, and velocity. The excursion portion of the MANOVA was measured using displacement and excursion. Velocity was measured by the mean velocity, peak velocity, and negative peak velocity. Variability was measured using the root mean square (RMS) and standard deviation (SD). Alpha level was set a priori at $\mathrm{p} \leq 0.05$. All statistical analyses were performed using SPSS (IBM SPSS Statistics for Windows, version 21.0; IBM Corp, Armonk, NY).

\section{Results}

Three MANOVAs were performed evaluating seven different variables that were grouped by measures of excursion, variability, and velocity. The descriptive statistics for excursion (Table 6), variability (Table 7), and velocity (Table 8) measures can be seen in Tables 6-8. There were no significant differences between groups for the excursion measures on the 
combined dependent variables $\mathrm{F}(8,38)=0.54, \mathrm{p}=0.82$; Wilks Lambda $=0.81$; partial eta squared $=0.10$ (Table 9). There were no significant differences between groups for the variability measures on the combined dependent variables $\mathrm{F}(8,76)=0.76$, $\mathrm{p}=0.63$; Wilks Lambda $=0.86$;

partial eta squared $=0.07$ (Table 9). There were no significant differences between groups for the velocity measures on the combined dependent variables $\mathrm{F}(12,72)=0.65$, $\mathrm{p}=0.79$; Wilks

Lambda $=0.82 ;$ partial eta squared $=0.10$ (Table 9).

Table 6. Descriptive Statistics: Excursion

\begin{tabular}{|c|c|c|c|}
\hline Variable & Group & Mean & SD \\
\hline \multirow{3}{*}{ Excursion $\mathrm{x}(\mathrm{cm})$} & Healthy & 3.76 & 1.14 \\
\hline & LAS Copers & 3.55 & 1.07 \\
\hline & CAI & 3.45 & 1.00 \\
\hline \multirow{3}{*}{ Excursion $\mathrm{y}(\mathrm{cm})$} & Healthy & 8.12 & 4.14 \\
\hline & LAS Copers & 8.36 & 2.33 \\
\hline & CAI & 8.05 & 2.61 \\
\hline \multirow{3}{*}{ Displacement $\mathrm{x}(\mathrm{cm})$} & Healthy & 0.87 & 0.58 \\
\hline & LAS Copers & 0.54 & 0.98 \\
\hline & CAI & -0.32 & 1.57 \\
\hline \multirow{3}{*}{ Displacement y (cm) } & Healthy & 0.99 & 1.64 \\
\hline & LAS Copers & 1.31 & 1.98 \\
\hline & CAI & 1.24 & 1.91 \\
\hline
\end{tabular}

Table 7. Descriptive Statistics: Variability

\begin{tabular}{|c|c|c|c|}
\hline Variable & Group & Mean & SD \\
\hline \multirow{3}{*}{ RMS $_{\text {X (cm) }}$} & Healthy & 0.54 & 0.12 \\
\cline { 2 - 4 } & LAS Copers & 0.57 & 0.13 \\
\cline { 2 - 4 } & CAI & 0.57 & 0.20 \\
\hline \multirow{3}{*}{ RMS $_{\text {Y }(\mathrm{cm})}$} & Healthy & 1.34 & 0.62 \\
\cline { 2 - 4 } & LAS Copers & 1.24 & 0.31 \\
\cline { 2 - 4 } & CAI & 1.24 & 0.44 \\
\hline \multirow{3}{*}{ SD $(\mathrm{cm})$} & Healthy & 1.47 & 0.41 \\
\cline { 2 - 4 } & LAS Copers & 1.71 & 0.67 \\
\cline { 2 - 4 } & CAI & 1.67 & 0.89 \\
\hline \multirow{3}{*}{ SD Y (cm) } & Healthy & 2.59 & 0.88 \\
\cline { 2 - 4 } & LAS Copers & 3.08 & 1.01 \\
\cline { 2 - 4 } & CAI & 2.72 & 0.87 \\
\hline
\end{tabular}


Table 8. Descriptive Statistics: Velocity

\begin{tabular}{|c|c|c|c|}
\hline Variable & Group & Mean & SD \\
\hline \multirow{3}{*}{ Mean Velocity X (cm/s) } & Healthy & 11.44 & 5.64 \\
\cline { 2 - 4 } & LAS Copers & 9.92 & 4.11 \\
\cline { 2 - 4 } & CAI & 11.43 & 5.12 \\
\hline \multirow{3}{*}{ Mean Velocity y (cm/s) } & Healthy & 18.83 & 6.58 \\
\cline { 2 - 4 } & LAS Copers & 22.83 & 10.57 \\
\cline { 2 - 4 } & CAI & 25.18 & 11.29 \\
\hline \multirow{3}{*}{ Peak Velocity X (cm/s) } & Healthy & 42.83 & 11.63 \\
\cline { 2 - 4 } & LAS Copers & 38.65 & 12.42 \\
\cline { 2 - 4 } & CAI & 38.46 & 19.48 \\
\hline \multirow{3}{*}{ Peak Velocity y (cm/s) } & Healthy & 55.46 & 12.40 \\
\cline { 2 - 4 } & LAS Copers & 80.18 & 47.56 \\
\cline { 2 - 4 } & CAI & 72.80 & 33.52 \\
\hline \multirow{2}{*}{ Negative Peak } & Healthy & -28.02 & 18.65 \\
\cline { 2 - 4 } Velocity X (cm/s) & LAS Copers & -24.83 & 12.62 \\
\cline { 2 - 4 } & CAI & -35.17 & 21.97 \\
\hline \multirow{2}{*}{$\begin{array}{c}\text { Negative Peak } \\
\text { Velocity y (cm/s) }\end{array}$} & Healthy & -50.41 & 32.25 \\
\cline { 2 - 4 } & LAS Copers & -60.71 & 36.62 \\
\cline { 2 - 4 } & CAI & -63.29 & 30.64 \\
\hline
\end{tabular}

Table 9. MANOVA Results

\begin{tabular}{|c|c|c|c|c|}
\hline & F & P- Value & Wilks Lambda & Partial Eta Squared \\
\hline Excursion & 0.54 & 0.82 & 0.81 & 0.10 \\
\hline Variability & 0.76 & 0.63 & 0.86 & 0.07 \\
\hline Velocity & 0.65 & 0.79 & 0.82 & 0.10 \\
\hline
\end{tabular}

\section{Discussion}

In the athletic population, there is a high frequency of lateral ankle sprains that occur in the United States each year. ${ }^{3}$ Most individuals that sustain a lateral ankle sprain will suffer from a recurrent injury. ${ }^{3}$ An abundance of research on individuals with ankle dysfunction has demonstrated that there are many potential contributing mechanical, neuromuscular, functional, and perceived deficits which may persist long after the tissues have been treated and healed following an acute ankle sprain. ${ }^{10-21}$ Due to the increased prevalence of lateral ankle sprains and individuals with ankle dysfunction, it has become pertinent to identify the differences that exist amongst populations affected by lateral ankle sprains. In our study, we analyzed 7 different COP 
variables during a SL hop task in different ankle dysfunction populations (CAI, LAS copers, and healthy individuals). Our results indicate that there were no statistically significant differences amongst groups.

A study found that there was no differences in functional performance between individuals with CAI and healthy controls during an agility hop test. ${ }^{33}$ Although complaints of subjective symptoms are often associated with chronic ankle instability, these symptoms do not negatively influence functional performance. ${ }^{33}$ This suggests that proprioceptive capabilities are still sufficient enough in individuals with CAI that they can still perform functional tasks at an optimal level. ${ }^{33}$ Therefore, it could be concluded that the tasks analyzed were not demanding enough to elicit performance differences amongst groups. ${ }^{33}$ This coincides with the lack of statistical differences seen between groups in our own study during a SL hop task.

In a study performed by Doherty et al, kinematic data showed individuals with CAI had biomechanical changes in hip movement and motor control patterns in the involved limb during both phases of a drop vertical jump. ${ }^{34}$ On the other hand, LAS copers may not display impairments in movement patterns since these compensations are not necessary for injury avoidance. ${ }^{8}$ Postural-control deficits seen in patients with CAI are thought to be a combination of impaired proprioception and neuromuscular control. ${ }^{6}$ People suffering from CAI typically have to use a different strategy to maintain their balance. ${ }^{35}$ This alteration seen in individuals with CAI is less efficient than a typical movement strategy for healthy individuals. ${ }^{6}$ However, this postural-control approach is most likely attributed to the changes in central neural control when there is an ankle-joint dysfunction present. ${ }^{6}$

In a study by Caffrey et al, they used subjective questionnaires and reports of instability during single-leg functional activities to classify individuals with functional ankle instability, a 
subgroup of CAI. ${ }^{36,37}$ They found that there were differences in performance time amongst 3 out of the 4 hopping tests they implemented in individuals with ankle dysfunction when compared to healthy individuals. ${ }^{36}$ These results coincide with prior studies that support the existence of performance deficits in individuals with ankle dysfunction during single-limb functional tests. ${ }^{38,39}$ Based off of these results, Caffrey proposed that while individuals with functional ankle instability have performance deficits, these deficits may range substantially depending on the individuals ankle dysfunction severity. ${ }^{36}$

According to existing evidence, differences in movement patterns exist between LAS copers and individuals with CAI across a variety of tasks and measures. ${ }^{8}$ Previous research has shown greater mechanical changes in individuals with CAI than LAS copers and healthy individuals. ${ }^{40}$ It is suggested that CAI places greater constraints on the sensorimotor system during functional tasks. ${ }^{41}$ These deficits result in a reorganization of postural control strategies and may be indicative of a diminished ability to respond effectively to the changes in postural control strategies. ${ }^{41}$

To the best of the author's knowledge, this was the first study to examine kinematic data to see if biomechanical differences exist amongst lateral ankle sprain copers and individuals with chronic ankle instability during a SL hop task. Based on differences seen amongst these pathologic populations in previous research, we hypothesized that there would be a clinically relevant biomechanical difference between LAS copers and CAI participants and that there would be a minimal difference between LAS copers and healthy individuals. Our hypotheses were not supported as there was no clinically relevant biomechanical differences between groups during a SL hop task. We believe that our SL hop task was too simple to elicit significant differences amongst groups since it involved vertical jumping over a stationary position. More 
complex dynamic tasks (cutting, lateral hopping, tri-planar SL hopping, etc.) may elicit group differences in patients with ankle dysfunction as they require more stability from the ankle complex. Although we did not observe statistically significant $\mathrm{p}$-values, this data helps to establish a foundation for future studies examining COP data throughout dynamic tasks within these specific patient populations.

Every study has its own set of strengths and limitations. A strength of this study was the study design itself, a case-control study. Case-control studies are able to easily look at specific populations of individuals as the participants are hand-selected. ${ }^{42}$ In this instance, participants were selected if they had ankle dysfunction and fit within each group's criteria parameters. Another strength of this study was the original research design, which combatted the testing, instrumentation, and expectancy threats to internal validity by having a consistent tester as well as blinding and randomization within the study. One of the major limitations within this study was the lack of additional data (severity of initial injury, ROM meausrements, etc.) to supplement the self-assessment survey data acquired from the participants as a basis for inclusion criteria for both the LAS coper and CAI groups. Additional data may have shown the severity of ankle dysfunction within the realm of CAI. The severity of ankle dysfunction can impact an individual's functional performance, which can make differences amongst groups range substantially depending on where the individual is located on the CAI spectrum. ${ }^{36}$

Future research should aim to continue studying these pathologic populations in order to fully understand the biomechanical differences that exist between groups. It is crucial to understand the mechanisms that differentiate a LAS coper and an individual with CAI in order to be able to one day solve the CAI epidemic. Further research should examine a more complex dynamic task that stresses the lateral ankle structures in order to fully comprehend if any 
biomechanical differences exist in people with ankle dysfunction. ${ }^{36}$ Time to boundary measures also need to be investigated as they have been shown to be more sensitive in detecting postural control deficits when compared to traditional measurements, such as COP data, in individuals with CAI. ${ }^{25,26}$

In conclusion, our findings suggest that there were no biomechanical differences present amongst individuals with ankle dysfunction during a SL hop task. Future research should examine a more difficult dynamic stabilization task since we believe that the SL hop was not difficult enough to truly examine the between groups differences that might exist. 


\title{
CHAPTER II: EXTENDED REVIEW OF THE LITERATURE
}

\begin{abstract}
Anatomy
It is pertinent to understand the anatomy of the ankle complex in order to fully understand the biomechanics of a lateral ankle sprain, which can lead to chronic ankle instability. Stability in the ankle joint is provided by the bony geometry of the joints themselves, ligaments, and muscular restraints that cross the joint.
\end{abstract}

\section{Bone/Joint}

The ankle complex is comprised of the subtalar, talocrural, talocalcaneonavicular, and inferior tibiofibular joints. ${ }^{43}$ The articulation between the talus and calcaneus forms the subtalar joint. The calcaneus is located inferiorly to the talus and that articulation forms a tri-planar, uniaxial joint. ${ }^{44}$ Due to the bony geometry of these two bones allows for inversion and eversion range of motion at the ankle. ${ }^{43}$ The talocrural joint is the junction between the distal tibia and distal fibula with the talus. The trochlea of the talus fits into the mortise of the distal tibia and fibula creating the talocrural joint. The distal ends of the long bones in the lower leg (tibia and fibula) have malleoli that constrain the talus making the talocrural joint a hinge joint. ${ }^{43}$ Plantarflexion and dorsiflexion are the motions most promoted at this joint. The bony geometry at the talocrural joint contributes a good amount of stability to the ankle joint as a whole and is most stable in dorsiflexion and resists eversion. ${ }^{43}$ The talocalcaneonavicular joint is the articulation between the talus, navicular, calcaneus and cuboid. Due to sharing a common axis of motion, this joint is often categorized as the same functional unit as the subtalar joint as they both contribute to eversion and inversion ranges of motion at the foot. ${ }^{45,46}$ The inferior tibiofibular joint is not a synovial articulating joint, however it is comprised of the interosseous 
membrane that connects the distal ends of the tibia and fibula. ${ }^{47}$ The primary function of this joint is stabilization through its ligamentous attachments. ${ }^{43}$

\section{Muscle}

Motion at the ankle joint is created by the twelve extrinsic muscles of the lower leg that originate at many different points in the lower leg and insert on the foot. ${ }^{43}$ These twelve muscles are divided up by their orientation into four fascial compartments: anterior, lateral, posterior, and deep posterior. The anterior compartment consists of the tibialis anterior, extensor hallucis longus, extensor digitorum longus, and peroneus tertius. The muscles in this compartment primarily dorsiflex the foot along with muscle specific secondary actions. The lateral compartment consists of the peroneus brevis and longus muscles that dorsiflex and evert the foot. The posterior compartment contains the gastrocnemius, soleus, and plantaris, which all plantarflex the foot. Lastly, the deep posterior compartment contains the flexor hallucis longus, flexor digitorum longus, and tibialis posterior. All three of these muscles in this compartment plantarflex and invert the foot.

\section{Ligament}

The ligaments of the talocrural joint are primarily located on the medial and lateral aspects of the talus. There are three major lateral ankle ligaments: the anterior talofibular ligament, calcaneofibular ligament, and posterior talofibular ligament. All of these ligaments help to prevent lateral ankle movement, otherwise known as inversion. ${ }^{48}$ The deltoid ligament complex supports the medial aspect of the ankle and can be divided into four bands: the tibionavicular, anterior tibiotalar, tibiocalcaneal, and posterior tibiotalar. ${ }^{48}$ Since there is a lack of muscular attaches on the talus, the stability of the subtalar joint comes primarily from the ligamentous support. ${ }^{49}$ The ligaments that comprise the subtalar joint are the interosseous 
talocalcaneal ligament, ligamentum cervicis, medial talocalcaneal ligament, lateral talocalcaneal ligament, and the posterior talocalcaneal ligament. ${ }^{49}$ The talocalcaneonvaicular joint is composed of one ligament: the plantar calcaneonavicular ("spring") ligament. ${ }^{49}$

\section{Pathomechanics of a Lateral Ankle Sprain}

The common mechanism of a lateral ankle sprain is when the foot is placed in plantar flexion and calcaneal inversion. These two movements place great stress on the ATFL and CFL and if the force is great enough, can cause a complete rupture of these ligaments. This is known as a grade 3 lateral ankle sprain. Regardless of the grade of lateral ankle sprain, ankle sprains can lead to pain and disability.

\section{Lateral Ligament Orientation and Order of Failure}

Stability on the lateral side of the ankle is provided by three major static stabilizing ligamentous structures: the anterior talofibular ligament (ATFL), calcaneofibular ligament (CFL), and the posterior talofibular ligament (PTFL). Each of these ligaments work together to provide joint stability at the ankle but also have independent roles and are responsible for limiting different motions at the talocrural joint. The AFTL lies on the dorsolateral aspect of the foot and is most often the first lateral ligament injured during an inversion ankle sprain. It plays a major role in preventing anterior translation of the talus. ${ }^{6}$ It has been reported that the ATFL is most often the first lateral ligament injured during an inversion ankle sprain because it has the lowest load to failure. ${ }^{6}$ The second most commonly injured lateral ankle ligament is the CFL, often in conjunction with the ATFL accounting for $20-25 \%$ of ankle sprains. ${ }^{50}$ The most lateral ankle ligament, the CFL is also injured during an inversion ankle sprain, however, when compared to the ATFL, the CFL is injured less in ankle sprain injuries. ${ }^{6}$ The major role of the CFL is to prevent calcaneal inversion. The last and most posterolateral ligamentous stabilizer is 
the PTFL. The major role of the PTFL is to prevent posterior translation of the talus on the tibia. Of the three lateral ligaments, the PTFL is rarely injured in an inversion ankle sprain. There are two reasons for this: 1) the PTFL has the highest load to failure and 2) the mechanism of injury for the PTFL is in contrast to that of the ATFL and the CFL. 3,6

\section{Dynamic Stabilization}

The muscles of the anterior and lateral compartments provide primary dynamic stabilization in preventing the ranges of motion that lead to acute lateral ankle sprains. Specifically, the muscles in the lateral compartment, peroneus longus and brevis, are an integral part of controlling the rate of inversion. ${ }^{51}$ The muscles of the anterior compartment provide restraint against rearfoot supination and thus ultimately controlling the rate of the plantarflexion moment of a lateral ankle sprain. ${ }^{6}$ Theoretically, if the muscles that eccentrically control inversion and plantarflexion fire efficiently, the rate of acute lateral ankle sprains should sufficiently decrease. ${ }^{52}$

In theory, the peroneal muscles should be able to provide a dynamic restraint to a lateral ankle sprain since they help to control the rate on inversion. ${ }^{51}$ Ashton-Miller et al estimated that the rate of inversion, upon landing, can occur as fast as 40 milliseconds. ${ }^{51}$ In a study done by Konradsen et al, it was concluded that it would take the peroneal muscles 126 milliseconds to respond after a sudden and unexpected inversion perturbation of the ankle. ${ }^{53}$ This 126 millisecond time frame was decided upon based off of the 54 milliseconds reaction time of initial electromyographic activity and the 72 milliseconds of electromyographic delay needed to generate force within the muscles to combat the inversion moment. ${ }^{53}$ In order for the peroneal muscles to generate the force needed to combat this sudden and unexpected inversion moment, preparatory muscle activation is imperative prior to foot contact. ${ }^{52,53}$ 


\section{Ankle Mortise Bony Congruency}

Due to the bony geometry of the ankle mortise, the ankle and foot are more prone to inversion ankle sprain injuries rather than eversion. ${ }^{6}$ Since the lateral malleolus of the fibula is longer than the medial malleolus of the tibia, more force is needed to injure the medial restraints from an eversion injury rather than the more commonly occurring injury to the lateral restraints in an inversion ankle sprain. ${ }^{6}$

\section{Pathomechanics of Chronic Ankle Instability}

Even though the mechanism of injury for both acute and recurrent lateral ankle sprains is the same, the changes that occur after the initial injury are what predispose individuals to recurrent sprains. ${ }^{4}$ The residual symptoms that linger following repetitive lateral ankle sprains are often correlated with chronic ankle instability (CAI). ${ }^{5}$ This condition is categorized by repetitive ankle sprains, decreased self-reported function due to the ankle injuries, and incidences of the ankle "giving way". 6 The two theories most often associated with the cause of CAI are mechanical and functional instability. ${ }^{6}$ Mechanical instability deals with anatomic abnormalities, whereas on the other hand functional instability is usually related to a proprioceptive deficit. ${ }^{54}$

\section{Mechanical Instability}

Mechanical instability occurs when there are anatomical changes after the initial lateral ankle sprain, which predisposes the ankle joint to further episodes of instability and recurrent ankle sprains. ${ }^{6}$ The anatomic changes that occur include, but are not limited to: pathologic laxity, impaired arthrokinematics, synovial changes, and the development of degenerative joint disease. ${ }^{6}$ These changes can be isolated or in conjunction with any of the above mentioned alterations. ${ }^{6}$

Pathologic laxity often occurs after ligamentous damage in an acute lateral ankle sprain and the extent of that laxity depends on the amount of damage that occurred at the initial injury. ${ }^{6}$ 
When the ankle is suspect to vulnerable positions (inversion and plantar flexion) during functional activities, pathologic laxity often plays a role in subsequent injury. ${ }^{6}$ Pathologic laxity in the ankle is typically seen in the talocrural and subtalar joints. ${ }^{55}$ The ATFL and CFL primarily cause instability at the talocrural joint, but can also cause instability of the subtalar joint as well. ${ }^{56}$ When there is damage to the ATFL, the talus is able to excessively supinate which predisposes an individual to a lateral ankle sprain. ${ }^{57}$ Patients with chronic ankle instability (CAI) often have pathologic laxity and shockingly even $11 \%$ of healthy individuals also have asymmetric ankle laxity as assessed by the talar tilt and anterior drawer tests. ${ }^{58}$

One of the major arthrokinematic impairments, another insufficiency in mechanical instability, is a positional fault at the inferior tibiofibular joint. ${ }^{6,59}$ Individuals with CAI, according to Mulligan et $\mathrm{al}^{59}$, may have an anteriorly and inferiorly displaced fibula putting the ATFL on slack in its resting position. ${ }^{6}$ Due to this positional laxity of the ATFL, when the rearfoot goes into supination the talus has greater range of motion. ${ }^{6}$ This allows for episodes of instability to occur and therefore leading to recurrent ankle sprains. ${ }^{6}$ Hypomobility of the ankle joint is another arthrokinematic impairment, often seen as a lack of dorsiflexion, that predisposes individuals to a lateral ankle sprain. ${ }^{60}$ A study done by Green et a ${ }^{61}$ demonstrated that the lack of dorsiflexion range of motion following a lateral ankle sprain could be attributed to altered arthrokinematics at the ankle mortise. Without sufficient dorsiflexion, the ankle may never reach its most stable position in the stance phase, the closed-pack position. ${ }^{6}$ During the stance phase, if the ankle can't reach its closed-pack position it is susceptible to lateral ankle sprains due to the lack of stability preventing inversion and internal rotation ranges of motion. ${ }^{6}$ 


\section{Functional Instability}

This is often a problem with the aforementioned dynamic stabilizers of the ankle and their resultant lack of efficient eccentric control of inversion and plantarflexion. This is due to changes in the neuromuscular system that ultimately provides dynamic support to the ankle. ${ }^{6}$ An article by Freeman et $\mathrm{al}^{62}$ first described the idea of functional instability and they concluded that balance impairments in people with lateral ankle sprains had actually damaged their articular mechanoreceptors in the lateral ankle ligaments. ${ }^{63}$ This damage led to a deficit in proprioception and therefore effected their balance. ${ }^{6}$ Even though the contribution of altered proprioception is an important factor it is not the sole factor in why ankle ligament injury predisposes individuals to functional ankle instability. ${ }^{6}$ Research has deemed functional instability, in individuals with either acute lateral ankle sprains or with CAI, as deficits in ankle proprioception, cutaneous sensation, nerve-conduction velocity, neuromuscular response times, postural control, and strength. ${ }^{6}$

While both impaired proprioception and cutaneous sensation contribute to functional instability, it is unknown to what extent they really affect instability at the ankle joint. ${ }^{6}$ In a study by Khin-Myo-Hla et $\mathrm{al}^{64}$, they suggested that altered muscle-spindle activity in the peroneal muscle group may be more of a contributor to the proprioceptive deficits at the ankle, rather than the aforementioned altered mechanoreceptor activity. The deficits often associated with CAI patients are typically seen in the peroneal muscles and this can be due to impaired proprioception, slowed nerve-conduction velocity, or central impairments in neuromuscularrecruitment strategies. ${ }^{6}$ Bullock-Saxton et al ${ }^{65}$ demonstrated that neuromuscular impairments are present in both structures that cross the affected ankle joint and neuromuscular pathways that 
exist in both limbs. This finding indicates that there are central neural adaptations that occur when there is a peripheral joint injury. ${ }^{6}$

Postural-control deficits in patients with CAI are thought to be a combination of impaired proprioception and neuromuscular control. ${ }^{6}$ Typically people with CAI exhibit a "hip strategy" to maintain their balance. ${ }^{35}$ This "hip strategy", as described by Pintsaar et al ${ }^{35}$, is when the hip is flexed or extended in the direction of the sway perturbation, which leads to a shear force against the support surface re-centering the center of mass over the center of support. Uninjured individuals often exhibit an "ankle strategy" in order to maintain a unilateral stance. ${ }^{35}$ This "ankle strategy" is comprised of muscle contractions that start at the ankle and generate a torque rotating the body towards the support surface. ${ }^{35}$ The alteration seen in the "hip strategy" is less efficient than the typically observed "ankle strategy" in uninjured individuals, however, this postural-control approach is most likely attributed to the changes in central neural control when there is an ankle-joint dysfunction present. ${ }^{6}$ The last known contributor to functional instability is a deficit in strength. Although strength deficits have been reported in patients with CAI, there isn't sufficient evidence to support the role and causation of these strength deficits. ${ }^{6}$

\section{Lateral Ankle Sprain Copers}

In Chronic Ankle Instability research, it is recommended to use lateral ankle sprain (LAS) copers as a comparison group to CAI patients by the International Ankle Consortium. ${ }^{7}$ By utilizing a comparison group, such as LAS copers, may provide stronger and more reliable results than compared to uninjured or healthy control subjects, due to the exposure to the injury and not developing CAI. ${ }^{8}$ These individuals successfully cope with the damage that results from sustaining a lateral ankle sprain, whereas CAI patients suffer from residual symptoms. ${ }^{8}$ 


\section{Definition}

LAS copers, as defined by Wikstrom et al., are "individuals that have a history of at least one LAS that occurred at least 12 months ago and do not complain of disability and/or giving way episodes since their injury." 8 Within the literature, there are three recommendations for key components in defining a LAS coper: 1) having sustained an initial LAS, 2) lack of CAI residual symptoms (disability, giving way, feeling unstable, etc.), and 3) a 12 month period of no subsequent LAS. ${ }^{8}$ The 12 month time period was chosen based on the risk of a recurrent LAS, modification of activity to resume to prior level, and within the literature it was a typical inclusion criteria for this specific population. ${ }^{9,21,66-77}$

\section{Minimal Inclusion Criteria}

In order to be deemed as a LAS coper, there are minimum inclusionary criteria that should be met to keep things consistent. Inclusion criteria should consist of an initial LAS severe enough to warrant immobilization and/or a protective device for at least a week, return to previous level of activity for a year without recurrent injury and/or feelings of instability, and minimal level of self-reported disability. ${ }^{8}$ In conjunction with the minimum inclusion criteria, there is additional recommended inclusion criteria to be used in research with LAS copers that includes no acute head and/or lower extremity injury within the past 3 months and a history of ankle fractures or surgeries. ${ }^{8}$ To better contextualize LAS copers amongst research, if possible, it is recommended to use the presence of pain as exclusion criteria in conjunction with the recommended and minimum inclusionary criteria as stated above with LAS copers. ${ }^{8}$ 


\section{Differences between CAI and LAS Copers}

\section{Self-Reported Disability}

LAS copers appear to report minimal self-reported disability and tend to self-report better ankle function when compared to individuals with CAI. ${ }^{8}$ In some cases, LAS copers appear to be equivalent to uninjured controls, which is why implementing LAS copers in CAI research is imperative in producing more significant results. ${ }^{8}$ In multiple studies using the Foot and Ankle Ability Measure-Activities of Daily Living (FAAM-ADL) and the Foot and Ankle Ability Measure-Sport (FAAM-S) self-reported function was higher in LAS copers than when compared to individuals with CAI and were equivalent to control subjects. ${ }^{71,73,77}$ Additionally, when used independently of reported inclusion criteria, LAS copers reported better function than individuals with CAI on questionnaires of ankle function. , $^{9,40}$

\section{Mechanical Changes}

Mechanical changes amongst individuals with CAI demonstrate greater anterior displacement and inversion rotation when compared to LAS copers with an instrumented arthrometer. ${ }^{40}$ However, some research reported no differences in ligament laxity amongst LAS

copers, CAI individuals, and control groups. ${ }^{78,79}$ LAS copers were not more likely to test positive to the anterior drawer ligament test when compared to subjects with CAI or controls, but LAS copers were more prone to test negative on a talar tilt test than those with CAI. ${ }^{77}$ Both individuals with CAI and LAS copers don't appear to have a difference with talar or fibular positions. $^{21,76} \mathrm{CAI}$ patients do not appear to have ligament laxity or other mechanical joint alterations based on current literature when compared to uninjured controls. ${ }^{8}$ Currently, in LAS copers, it is unclear if they have mechanical joint alterations relative to uninjured controls. ${ }^{8}$ 


\section{Sensorimotor Alterations}

According to existing evidence, differences in movement patterns exist between LAS copers and individuals with CAI across a variety of tasks and measures. ${ }^{8}$ According to a study done by Doherty et al, there was kinematic data that individuals with CAI displayed an increase in hip flexion in the involved limb during both phases of a drop vertical jump. ${ }^{34}$ Participants with CAI displayed changes in hip movement and motor control patterns when compared to the LAS copers; these findings may give an indication to the coping mechanism following the initial LAS injury that leads to CAI. ${ }^{34}$ Neuromuscular control in LAS copers may not be impaired as movement patterns avoid an increase in injury risk. ${ }^{8}$ Since it is the thought that the hip plays an important role in the development of CAI, clinicians must integrate rehabilitation programs that include focus on proximal joints as well as the injured ankle; specifically in neuromuscular control as a global concept. ${ }^{34}$ By integrating these rehabilitative techniques that focus on the entire kinetic chain, the ultimate goal is to guide patients towards a LAS coper path rather than a CAI path. ${ }^{34}$

\section{Recent Research}

Chronic ankle instability is a heavily researched topic, but the inclusion of lateral ankle sprain copers as a comparison group has only been recently researched within the past 20 years. ${ }^{7}$ Due to the increased prevalence of using lateral ankle sprain copers as a comparison group in research, Wikstrom et al. established minimum reporting standards for LAS copers in CAI research primarily based off of previous research in $2014 .{ }^{8}$ This was pivotal in producing consistent and reliable findings amongst CAI research. ${ }^{45}$ Within CAI research, there has been ample research conducted with the use of stationary tasks examining various variables. However, there has been little to no research performed examining these groups within a dynamic task. 
Therefore, the purpose of this study was to determine the differences that exist amongst lateral ankle sprain copers and individuals with chronic ankle instability in a dynamic single leg hopping task analysis. 


\section{REFERENCES}

1. Kaminski TW, Hertel J, Amendola N, et al. National Athletic Trainers' Association position statement: conservative management and prevention of ankle sprains in athletes. J Athl Train. 2013;48(4):528-545.

2. Adams J BE, Collings J, DeBlieux P, Gisondi M, Nadel E. Emergency Medicine. In: Philadelphia, PA: Elsevier; 2008:897-898.

3. Golanó P, Vega J, de Leeuw PA, et al. Anatomy of the ankle ligaments: a pictorial essay. Knee Surg Sports Traumatol Arthrosc. 2010;18(5):557-569.

4. Hintermann B. Biomechanics of the unstable ankle joint and clinical implications. Med Sci Sports Exerc. 1999;31(7 Suppl):S459-469.

5. Hoch MC, Mullineaux DR, Andreatta RD, et al. Effect of a 2-week joint mobilization intervention on single-limb balance and ankle arthrokinematics in those with chronic ankle instability. J Sport Rehabil. 2014;23(1):18-26.

6. Hertel J. Functional Anatomy, Pathomechanics, and Pathophysiology of Lateral Ankle Instability. J Athl Train. 2002;37(4):364-375.

7. Hertel J, Kaminski TW. Second international ankle symposium summary statement. $J$ Orthop Sports Phys Ther. 2005;35(5):A2-6.

8. Wikstrom EA, Brown CN. Minimum reporting standards for copers in chronic ankle instability research. Sports Med. 2014;44(2):251-268.

9. Wikstrom EA, Tillman MD, Chmielewski TL, Cauraugh JH, Naugle KE, Borsa PA. Selfassessed disability and functional performance in individuals with and without ankle instability: a case control study. J Orthop Sports Phys Ther. 2009;39(6):458-467. 
10. MA F. Instability of the foot after injuries to the lateral ligament of the ankle. In. Vol 47: J Bone Joint Surg Br; 1965:669-677.

11. Hiller CE, Nightingale EJ, Lin CW, Coughlan GF, Caulfield B, Delahunt E. Characteristics of people with recurrent ankle sprains: a systematic review with metaanalysis. Br J Sports Med. 2011;45(8):660-672.

12. Arnold BL, De La Motte S, Linens S, Ross SE. Ankle instability is associated with balance impairments: a meta-analysis. Med Sci Sports Exerc. 2009;41(5):1048-1062.

13. Brinkman RE, Evans TA. History of ankle sprain as a risk factor of future lateral ankle sprain in athletes. J Sport Rehabil. 2011;20(3):384-388.

14. Hertel J. Sensorimotor deficits with ankle sprains and chronic ankle instability. Clin Sports Med. 2008;27(3):353-370, vii.

15. D H, CL D, J S. Severity of functional and mechanical ankle instability in an active population. In. Vol 30: Foot Ankle Int; 2009:1071-1077.

16. Hubbard TJ, Kramer LC, Denegar CR, Hertel J. Contributing factors to chronic ankle instability. Foot Ankle Int. 2007;28(3):343-354.

17. Hubbard-Turner T. Relationship between mechanical ankle joint laxity and subjective function. Foot Ankle Int. 2012;33(10):852-856.

18. McKeon PO, Hertel J. Systematic review of postural control and lateral ankle instability, part I: can deficits be detected with instrumented testing. J Athl Train. 2008;43(3):293304.

19. Munn J, Sullivan SJ, Schneiders AG. Evidence of sensorimotor deficits in functional ankle instability: a systematic review with meta-analysis. J Sci Med Sport. 2010;13(1):212. 
20. Sefton JM, Hicks-Little CA, Hubbard TJ, et al. Sensorimotor function as a predictor of chronic ankle instability. Clin Biomech (Bristol, Avon). 2009;24(5):451-458.

21. Wikstrom EA, Tillman MD, Chmielewski TL, Cauraugh JH, Naugle KE, Borsa PA. Discriminating between copers and people with chronic ankle instability. J Athl Train. 2012;47(2):136-142.

22. Mettler A, Chinn L, Saliba SA, McKeon PO, Hertel J. Balance training and center-ofpressure location in participants with chronic ankle instability. $J$ Athl Train. 2015;50(4):343-349.

23. Bastien M, Moffet H, Bouyer LJ, Perron M, Hébert LJ, Leblond J. Alteration in global motor strategy following lateral ankle sprain. BMC Musculoskelet Disord. 2014;15:436.

24. Delahunt E, Monaghan K, Caulfield B. Altered neuromuscular control and ankle joint kinematics during walking in subjects with functional instability of the ankle joint. Am J Sports Med. 2006;34(12):1970-1976.

25. McKeon PO, Ingersoll CD, Kerrigan DC, Saliba E, Bennett BC, Hertel J. Balance training improves function and postural control in those with chronic ankle instability. Med Sci Sports Exerc. 2008;40(10):1810-1819.

26. Hertel J, Olmsted-Kramer LC. Deficits in time-to-boundary measures of postural control with chronic ankle instability. Gait Posture. 2007;25(1):33-39.

27. Palmieri R, Ingersoll C. Center-of-pressure parameter used in the assessment of postural control. In. Vol 11: J Sport Rehabilitation; 2002:51-66.

28. Riemann BL. Is There a Link Between Chronic Ankle Instability and Postural Instability? J Athl Train. 2002;37(4):386-393. 
29. Ross SE, Guskiewicz KM. Examination of static and dynamic postural stability in individuals with functionally stable and unstable ankles. Clin J Sport Med. 2004;14(6):332-338

30. Jagodinsky A. The Effect of Ankle Bracing on Lower Extremity Coordination, Coordination Variability, and Neuromuscular Activity in Individuals with and without Chronic Ankle Instability. In: Auburn University; 2016:180.

31. Jagodinsky A. The Effect of Ankle Bracing on Lower Extremity Coordination, Coordination Variability, and Neuromuscular Activity in Individuals with and without Chronic Ankle Instability. In: Auburn University; 2016:180.

32. Gribble PA, Delahunt E, Bleakley CM, et al. Selection criteria for patients with chronic ankle instability in controlled research: a position statement of the International Ankle Consortium. J Athl Train. 2014;49(1):121-127.

33. Demeritt KM, Shultz SJ, Docherty CL, Gansneder BM, Perrin DH. Chronic Ankle Instability Does Not Affect Lower Extremity Functional Performance. J Athl Train. 2002;37(4):507-511.

34. Doherty C, Bleakley C, Hertel J, et al. Coordination and Symmetry Patterns During the Drop Vertical Jump in People With Chronic Ankle Instability and Lateral Ankle Sprain Copers. Phys Ther. 2016;96(8):1152-1161.

35. Pintsaar A, Brynhildsen J, Tropp H. Postural corrections after standardised perturbations of single limb stance: effect of training and orthotic devices in patients with ankle instability. Br J Sports Med. 1996;30(2):151-155. 
36. Caffrey E, Docherty CL, Schrader J, Klossner J. The ability of 4 single-limb hopping tests to detect functional performance deficits in individuals with functional ankle instability. J Orthop Sports Phys Ther. 2009;39(11):799-806.

37. Hiller CE, Kilbreath SL, Refshauge KM. Chronic ankle instability: evolution of the model. J Athl Train. 2011;46(2):133-141.

38. Docherty CL, Arnold BL, Gansneder BM, Hurwitz S, Gieck J. Functional-Performance Deficits in Volunteers With Functional Ankle Instability. J Athl Train. 2005;40(1):30-34.

39. Jerosch J BM. Proprioceptive capabilities of the ankle in stable and unstable joints. In. Vol 2: Sports Exerc Inj.; 1996:167-171.

40. Hubbard TJ. Ligament laxity following inversion injury with and without chronic ankle instability. Foot Ankle Int. 2008;29(3):305-311.

41. McKeon PO, Hertel J. Spatiotemporal postural control deficits are present in those with chronic ankle instability. BMC Musculoskelet Disord. 2008;9:76.

42. Thomas JR, Nelson, J. K., \& Silverman,, J. S. Research Methods in Physical Activity. 7th ed. Champaign, IL: Human Kinetics 2015.

43. Brockett CL, Chapman GJ. Biomechanics of the ankle. Orthop Trauma. 2016;30(3):232238.

44. R C. Foot and Ankle Pain. In: FA Davis Company; 1968.

45. Michael JM, Golshani A, Gargac S, Goswami T. Biomechanics of the ankle joint and clinical outcomes of total ankle replacement. J Mech Behav Biomed Mater. 2008;1(4):276-294.

46. Sarrafian SK. Biomechanics of the subtalar joint complex. Clin Orthop Relat Res. 1993(290):17-26. 
47. Procter P, Paul JP. Ankle joint biomechanics. J Biomech. 1982;15(9):627-634.

48. Kaumeyer G, Malone TR. Ankle injuries: anatomical and biomechanical considerations necessary for the development of an injury prevention program. J Orthop Sports Phys Ther. 1980;1(3):171-171.

49. Starkey C, Brown SD, Ryan J. Examination of Orthopedic and Athletic Injuries. 3 ed: F.A. Davis Company; 2010.

50. Renström PA, Konradsen L. Ankle ligament injuries. Br J Sports Med. 1997;31(1):11-20.

51. Ashton-Miller JA, Ottaviani RA, Hutchinson C, Wojtys EM. What best protects the inverted weightbearing ankle against further inversion? Evertor muscle strength compares favorably with shoe height, athletic tape, and three orthoses. Am J Sports Med. 1996;24(6):800-809.

52. Sinkjaer T, Toft E, Andreassen S, Hornemann BC. Muscle stiffness in human ankle dorsiflexors: intrinsic and reflex components. J Neurophysiol. 1988;60(3):1110-1121.

53. Konradsen L, Voigt M, Højsgaard C. Ankle inversion injuries. The role of the dynamic defense mechanism. Am J Sports Med. 1997;25(1):54-58.

54. Bonnel F, Toullec E, Mabit C, Tourné Y, Sofcot. Chronic ankle instability: biomechanics and pathomechanics of ligaments injury and associated lesions. Orthop Traumatol Surg Res. 2010;96(4):424-432.

55. Martin DE, Kaplan PA, Kahler DM, Dussault R, Randolph BJ. Retrospective evaluation of graded stress examination of the ankle. Clin Orthop Relat Res. 1996(328):165-170.

56. Rasmussen O, Tovborg-Jensen I. Mobility of the ankle joint: recording of rotatory movements in the talocrural joint in vitro with and without the lateral collateral ligaments of the ankle. Acta Orthop Scand. 1982;53(1):155-160. 
57. Bremer SW. The unstable ankle mortise--functional ankle varus. J Foot Surg. 1985;24(5):313-317.

58. Scranton PE, McDermott JE, Rogers JV. The relationship between chronic ankle instability and variations in mortise anatomy and impingement spurs. Foot Ankle Int. 2000;21(8):657-664.

59. Mulligan B. Manual Therapy: “NAGS”, “SNAGS”, “MWMS”, Etc. In. 3rd ed. Wellington, New Zealand1995:Plane View Services LTD.

60. Tabrizi P, McIntyre WM, Quesnel MB, Howard AW. Limited dorsiflexion predisposes to injuries of the ankle in children. $J$ Bone Joint Surg Br. 2000;82(8):1103-1106.

61. Green T, Refshauge K, Crosbie J, Adams R. A randomized controlled trial of a passive accessory joint mobilization on acute ankle inversion sprains. Phys Ther. 2001;81(4):984994.

62. Freeman M. Instability of the foot after injuries to the lateral ligament of the ankle. In. Vol 47: J Bone Joint Surg Br; 1965:669-677.

63. Freeman MA, Dean MR, Hanham IW. The etiology and prevention of functional instability of the foot. J Bone Joint Surg Br. 1965;47(4):678-685.

64. Khin-Myo-Hla, Ishii T, Sakane M, Hayashi K. Effect of anesthesia of the sinus tarsi on peroneal reaction time in patients with functional instability of the ankle. Foot Ankle Int. 1999;20(9):554-559.

65. Bullock-Saxton JE, Janda V, Bullock MI. The influence of ankle sprain injury on muscle activation during hip extension. Int J Sports Med. 1994;15(6):330-334. 
66. Verhagen E, van der Beek A, Twisk J, Bouter L, Bahr R, van Mechelen W. The effect of a proprioceptive balance board training program for the prevention of ankle sprains: a prospective controlled trial. Am J Sports Med. 2004;32(6):1385-1393.

67. Eastlack ME, Axe MJ, Snyder-Mackler L. Laxity, instability, and functional outcome after ACL injury: copers versus noncopers. Med Sci Sports Exerc. 1999;31(2):210-215.

68. Brown C. Foot clearance in walking and running in individuals with ankle instability. Am J Sports Med. 2011;39(8):1769-1776.

69. Brown C, Bowser B, Simpson KJ. Movement variability during single leg jump landings in individuals with and without chronic ankle instability. Clin Biomech (Bristol, Avon). 2012;27(1):52-63.

70. Brown CN, Padua DA, Marshall SW, Guskiewicz KM. Variability of motion in individuals with mechanical or functional ankle instability during a stop jump maneuver. Clin Biomech (Bristol, Avon). 2009;24(9):762-768.

71. Croy T, Saliba SA, Saliba E, Anderson MW, Hertel J. Differences in lateral ankle laxity measured via stress ultrasonography in individuals with chronic ankle instability, ankle sprain copers, and healthy individuals. J Orthop Sports Phys Ther. 2012;42(7):593-600.

72. Liu K, Glutting J, Wikstrom E, Gustavsen G, Royer T, Kaminski TW. Examining the diagnostic accuracy of dynamic postural stability measures in differentiating among ankle instability status. Clin Biomech (Bristol, Avon). 2013;28(2):211-217.

73. Plante JE, Wikstrom EA. Differences in clinician-oriented outcomes among controls, copers, and chronic ankle instability groups. Phys Ther Sport. 2013;14(4):221-226.

74. Wikstrom EA, Fournier KA, McKeon PO. Postural control differs between those with and without chronic ankle instability. Gait Posture. 2010;32(1):82-86. 
75. Wikstrom EA, Hass CJ. Gait termination strategies differ between those with and without ankle instability. Clin Biomech (Bristol, Avon). 2012;27(6):619-624.

76. Wikstrom EA, Tillman MD, Chmielewski TL, Cauraugh JH, Naugle KE, Borsa PA. Dynamic postural control but not mechanical stability differs among those with and without chronic ankle instability. Scand J Med Sci Sports. 2010;20(1):e137-144.

77. Wright CJ, Arnold BL, Ross SE, Ketchum J, Ericksen J, Pidcoe P. Clinical examination results in individuals with functional ankle instability and ankle-sprain copers. $J$ Athl Train. 2013;48(5):581-589.

78. Miller H, Needle AR, Swanik CB, Gustavsen GA, Kaminski TW. Role of external prophylactic support in restricting accessory ankle motion after exercise. Foot Ankle Int. 2012;33(10):862-869.

79. Gutierrez GM, Knight CA, Swanik CB, et al. Examining neuromuscular control during landings on a supinating platform in persons with and without ankle instability. Am $J$ Sports Med. 2012;40(1):193-201. 